\title{
Association Between Implementation of the Athlete Biological Passport and Female Elite Runners' Performance
}

\author{
Sergei Iljukov, Jukka-Pekka Kauppi, Arja L.T. Uusitalo, Juha E. Peltonen, and Yorck O. Schumacher
}

\begin{abstract}
The purpose of this research was to evaluate the performances of female middle- and long-distance runners before and after the implementation of a new antidoping strategy (the Athlete Biological Passport [ABP]) in a country accused of systematic doping. A retrospective analysis of the results of Russian National Championships from 2008 to 2017 was performed. The 8 best female performances for the $800-\mathrm{m}, 1500-\mathrm{m}, 3000-\mathrm{m}$ steeplechase, 5000-m, and 10,000-m events from the semifinals and finals were analyzed. The yearly number of athletes fulfilling standard qualifications for international competitions was also evaluated. Overall, numbers of athletes banned for doping in 2008-2017 were calculated. As a result, 4 events (800, 1500, 5000 [all $P<.001]$, and $10,000 \mathrm{~m}[P<.01])$ out of 5 showed statistically significant deterioration in the performances when comparing before and after the introduction of the ABP. The 3000-m steeplechase was the only event that did not show statistically significant change. The highest relative decrease in the number of runners who met standard qualification for international competition was for the 5000-m event (46\%), followed by 1500-m (42\%), 800-m (38\%), 10,000-m (17\%), and 3000-m steeplechase $(1 \%)$. In conclusion, implementation of the ABP was followed by a significant reduction in the performance of female runners in a country accused of systematic doping. It can be reasonably speculated that more stringent antidoping testing, more specifically the introduction of the ABP, is a key reason for this reduction.
\end{abstract}

Keywords: antidoping, World Anti-Doping Agency, doping in sports, blood doping

The use of performance-enhancing drugs in sports dates back centuries and has continued throughout the history of athletic competition. ${ }^{1}$ In the middle of the 20th century with the instrumentalization of sports for political purposes during the Cold War, the scale of doping changed and, in a number of countries, was supported by state-run organizations. ${ }^{2,3}$ There have been indications that in some countries such structures have continued to persist, which has translated to a much higher prevalence of doping compared with other nations. ${ }^{4}$

During the history of modern sports, different strategies and rules for the fight against doping were initiated by sports governing bodies. For track-and-field competitions, the first draft of a list of banned substances in sports was introduced by the International Association of Athletic Federations as early as 1928. Anabolic steroid testing was introduced in 1974 and regular out-of-competition tests in 1989. ${ }^{1}$

\footnotetext{
(C) 2020 The Authors. Published by Human Kinetics, Inc. This is an Open Access article distributed under the terms of the Creative Commons Attribution-NonCommercial-NoDerivatives 4.0 International License, CC BY-NC-ND 4.0, which permits the copy and redistribution in any medium or format, provided it is not used for commercial purposes, no modifications are made, appropriate credit is given, and a link to the license is provided. See http://creativecommons.org/licenses/ by-nc-nd/4.0. This license does not cover any third-party material that may appear with permission in the article. For commercial use, permission should be requested from Human Kinetics, Inc., through the Copyright Clearance Center (http://www. copyright.com).
}

Iljukov, Uusitalo, and Peltonen are with the Dept of Sports and Exercise Medicine, Clinicum, University of Helsinki, Helsinki, Finland. Iljukov is also with KIHUResearch Inst for Olympic Sports, Jyväskylä, Finland. Kauppi is with the Faculty of Information Technology, University of Jyväskylä, Jyväskylä, Finland. Uusitalo and Peltonen are also with the Clinic for Sports and Exercise Medicine, Foundation for Sports and Exercise Medicine, Helsinki, Finland. Schumacher is with Aspetar Orthopedic and Sports Medicine Hospital, Doha, Qatar. Iljukov (sergei.iljukov@ gmail.com) is corresponding author.
A number of studies related the introduction of out-ofcompetition doping testing to a decrease of performance in a range of sports disciplines. ${ }^{5-7}$ It is reasonable to associate stagnation or regression in peak competition results with new anti-doping strategies, as the primary aim of doping is an improvement in athletic performance, which seems to be plateauing in many disciplines. ${ }^{8,9}$

One of the recent anti-doping strategies is the implementation of the Athlete Biological Passport (ABP). ${ }^{10}$ The ABP is based on a collection of blood markers from an athlete in a longitudinal and individual way. Deviations from individually calculated reference ranges can indicate the use of forbidden substances or methods. Successful experiences with the ABP have been reported by several international sporting bodies. ${ }^{11}$

As performance improvement is the primary goal of doping, it was proposed that changes in performance levels could be used for assessment of new anti-doping strategies efficiency. ${ }^{12,13}$ Considering this framework, the goal of the present investigation was to assess the athletic performances before and after the implementation of an ABP program in a country with a known high prevalence of doping. ${ }^{4}$ We chose sporting disciplines that have been historically affected by doping and where the country was internationally dominant for decades. ${ }^{14}$

\section{Materials and Methods}

We extracted the 8 best performances from semifinals and finals (measured as running times) from different female track runners at Russian National Championships from 2008 to 2017. A publicly available database www.tilastopaja.com was used as the source for the data. As our data are based on publicly available resources, no informed consent was obtained. This study was conducted in accordance with the Declaration of Helsinki. Distances of 800-m, 1500-m, 3000-m steeplechase, 5000-m, and 10,000-m events were 
chosen for analysis. Track disciplines are less prone to external confounding factors affecting performance results. Unlike in marathon or cross-country running where the same distance is run on different routes and may vary to a significant extent due to environmental factors and race course design, track disciplines are more standardized, thus making the results comparable over years. The period from 2008 to 2017 was selected as it comprises a time period prior to the implementation of the ABP (in 2009) and a time period after. ABP profiles were built from 2009 onwards, and they have provided sufficient information since 2011. The first sanctions based on the data were handed out around this time. Thus, it was assumed that the ABP impacted performance from 2012 onwards. Therefore, 2012 was chosen as the year to differentiate periods "before" and "after" the introduction of the ABP. Female middle- and long-distance runners were chosen for this analysis due to their international success and long-standing European dominance. ${ }^{14}$ Due to their level of success, it is strongly assumed that most of the athletes were part of the International Association of Athletic Federations and Russian Anti-Doping Agency testing pool and thus the ABP program.

\section{Statistical Analysis}

\section{Performance Data}

For the purpose of statistical analysis, we first split the performance data into 2 groups: the best 8 running times for each year's championship (1 time per runner per year) between the years 2008 and 2012 (group G1, representing running times before the introduction of the $\mathrm{ABP}$ ) and the best 8 running times for each year between the years 2013 and 2017 (group G2, representing running times after the ABP is assumed to have had an effect on performance). Our null hypothesis was that there is no difference in the running results before and after the introduction of the ABP. Our alternative hypothesis was that the results are significantly slower after the introduction of the ABP. To assess whether there is a significant difference in running times between the groups, we used a permutation test designed for partially paired continuous data (for more details of the analysis procedure, see "Performance data analysis" in the Supplementary Material [available online]). ${ }^{15}$

\section{Number of Athletes Qualifying for Major International Competitions}

To allow an international perspective, we also determined the number of athletes in each discipline who met the highest international qualifying standards for the participation in major athletic competitions with their performance result at the National championships. The A qualification standards for the 2008 Olympic Games in Beijing (China), 2009 World Championship in Berlin (Germany), 2010 European Championship in Barcelona (Spain), 2011 World Championship in Daegu (South Korea), 2012 Olympic Games in London (Great Britain), 2013 World Championship in Moscow (Russia), 2014 European Championship in Zurich (Switzerland), 2015 World Championship in Beijing (China), 2016 Olympic Games in Rio de Janeiro (Brazil), and 2017 World Championship in London (Great Britain) were used for this purpose.

We assessed whether there was a statistically significant decrease in the number of athletes meeting the highest standard qualification for international competitions after the introduction of the ABP. For this purpose, we used a weighted chi-square test of homogeneity, ${ }^{16}$ which is applicable for partially paired categorical data (for more details, see "A-standard performance analysis" in the Supplementary Material [available online]). Furthermore, to reflect the relationship of ABP implementation on performance, we calculated the total number of athletes who qualified for international competitions and those who were eventually sanctioned for doping. For additional clarity, we counted the number of athletes sanctioned on ABP grounds and for other anti-doping rules violations. These calculations were divided into 2 periods: 2008-2012 and 2013-2017.

All statistical analyses procedures used in this study were implemented using the MATLAB (The MathWorks Inc, Natick, MA). Moreover, because we analyzed 5 distances, the obtained $P$ values for each distance were corrected for multiple comparisons using Bonferroni corrections.

\section{Results}

While excellent performance per se is not an indication of any wrongdoing, performance monitoring may provide an additional value in the assessment of anti-doping strategies. As was demonstrated in previous studies, some major changes in performance levels have historically followed implementation of new antidoping strategies..$^{5-9,13}$ In our investigation, we analyzed changes in the competition performance of Russian female middle- and long-distance runners before and after implementation of the ABP. To our knowledge, this research is the first to investigate the relationship of ABP implementation on athletic performance.

Figure 1 shows the average running performances (times) before and after the implementation of the ABP. Four events $(800$, 1500,5000 , and $10,000 \mathrm{~m}$ ) out of 5 showed a statistically significant increase in running times (ie, deterioration in the performances) with implementation of the ABP (see Table 1). The highest relative decrease in running performance was observed for the 5000-m (3.4\%, $P<.001)$, followed by $10,000-\mathrm{m}(2.6 \%, P=.007), 1500-\mathrm{m}$ (2.2\%, $P<.001), 800-\mathrm{m}(2.0 \%, P<.001)$, and 3000-m steeplechase $(0.4 \%, P=.322)$. The $3000-\mathrm{m}$ steeplechase was the only event that did not show statistically significant deterioration in the running performance after the introduction of the ABP.

The effect of the ABP implementation on the number of A qualification standard runners for different events is shown in Figure 2. For 800-, 1500-, and 5000-m events, there was a decrease in the number of A standard runners after the introduction of the ABP (see Table 2). The highest relative decrease in the number of A standard runners was observed for the 5000-m event $(46.2 \%$, $P=.001)$, followed by $1500-\mathrm{m}(42.1 \%, P<.001), 800-\mathrm{m}(38.1 \%$, $P<.001), 10,000-\mathrm{m}(16.7 \%, P=.050)$, and 3000-m steeplechase (10.0\%, $P=.346)$ events. Overall, $53 \%$ of athletes who fulfilled qualification standards in 2008-2012 were sanctioned for doping; 29 of them were sanctioned on grounds of the ABP and 11 for other doping agents and anti-doping rules violations. In 2013-2017, 9 athletes were sanctioned based on the ABP and 6 on grounds of conventional doping test results. Thus, altogether, $30 \%$ of athletes who qualified for international competitions in 2013-2017 were eventually banned for doping.

\section{Discussion}

There is a lack of studies investigating the efficiency of current anti-doping strategies. Performance monitoring and profiling were proposed as a potential tool for the measurement of anti-doping effectiveness. ${ }^{12,13}$ 

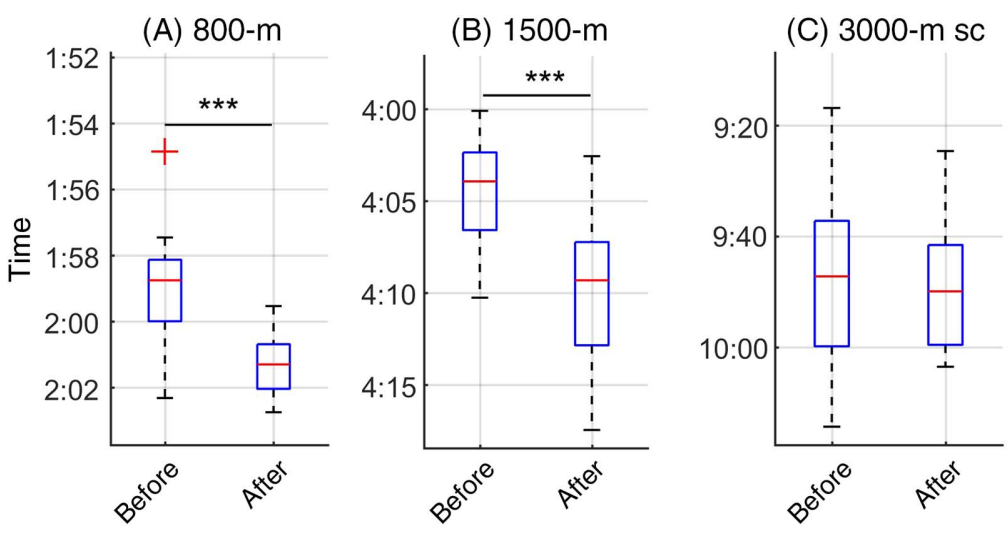

(D) $5000-m$

(E) $10,000-m$
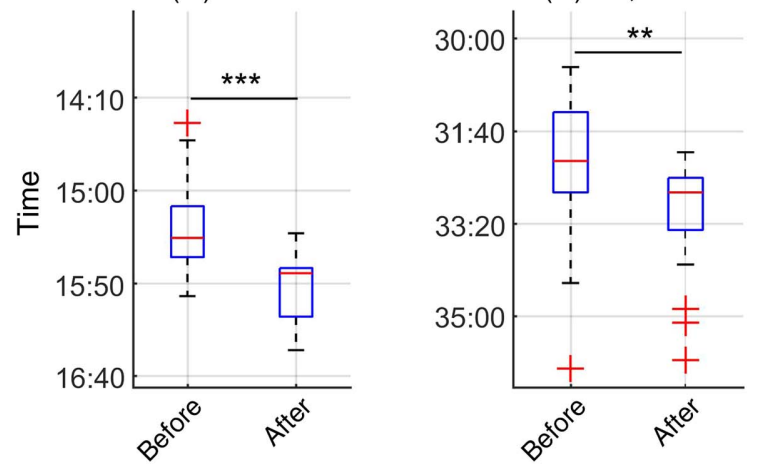

Figure 1 - Box plots of the running times (in minutes:seconds) in the 2 groups before and after the implementation of the Athlete Biological Passport for different events: (A) 800-m, (B) 1500-m, (C) 3000-m sc, (D) 5000-m, and (E) 10,000-m event. The central horizontal line inside each box shows the median, and the horizontal edges of the box denote the 25th and 75th percentiles of the running time distribution. The whiskers correspond to the data coverage of $\pm 2.7 \sigma$, and individual data points outside this coverage are marked with the " + " symbol. Events showing a statistically significant deterioration in performance after implementation of the ABP are denoted by asterisks (weighted mean difference statistics, see Supplementary Material [available online] for more details): $* * P<.01 ; * * * P<.001$. Abbreviation: sc indicates steeplechase.

Table 1 Change in Running Performance With the Implementation of the Athlete Biological Passport

\begin{tabular}{lcccc}
\hline Event & $\boldsymbol{\Delta} \boldsymbol{s}$ & $\boldsymbol{\Delta} \%$ & $\boldsymbol{T}_{\mathbf{w}}$ & $\boldsymbol{P}$ \\
\hline $800 \mathrm{~m}$ & 2.33 & 2.0 & -6.25 & $<.001$ \\
$1500 \mathrm{~m}$ & 5.26 & 2.2 & -5.61 & $<.001$ \\
$3000 \mathrm{~m} \mathrm{sc}$ & 2.31 & 0.4 & -0.50 & .322 \\
$5000 \mathrm{~m}$ & 31.60 & 3.4 & -5.63 & $<.001$ \\
$10,000 \mathrm{~m}$ & 49.83 & 2.6 & -2.72 & .007 \\
\hline
\end{tabular}

Abbreviations: $\Delta s$, absolute change in the average running time (in seconds) between 2008-2012 and 2013-2017 periods; $\Delta \%$, relative change in the average running time between 2008-2012 and 2013-2017 periods; sc, steeplechase; $T_{w}$, weighted mean difference statistics between 2008-2012 and 2013-2017 periods; $P$, Bonferroni-corrected $P$ values for $T_{w}$. Note: The numeric data from Figure 1 with more detailed information are presented in this table. A negative value of $T_{\mathrm{w}}$ means decrease in running performance (ie, increase in running time) with the Athlete Biological Passport implementation.

\section{Changes in Performance}

The results of our analysis reveal a significant drop in female athletes' performance for 800-, 1500-, 5000-, and 10,000-m disciplines after implementation of the ABP. For 800-, 1500-, and 5000-m events, this deterioration was most notable: 2.33 seconds (1.9\%), 5.26 seconds (2.1\%), 31.60 seconds (3.4\%) accordingly
$(P<.001)$, and 49.83 seconds $(2.6 \%)$ for the $10,000 \mathrm{~m}(P<.01)$ (Figure 1 and Table 1). Contrary to these findings, the 3000-m steeplechase performance decrease between 2008-2012 and 20132017 periods was only 2.31 seconds $(0.4 \%)$ and was not statistically significant.

The exception of the steeplechase results could be explained by the fact that this discipline was only accepted into the World Championship program in 2005. Traditionally, steeplechase is also a discipline that was not nurtured in Russia. Furthermore, steeplechase has a more multifactorial performance profile, where athletes have to jump barriers, which adds a certain skill level on top of the pure running performance.

The magnitude of performance changes found in our study is comparable with those caused by means of blood doping. There are a number of earlier studies investigating the effects of blood boosting on running performance. ${ }^{17-19}$ The autologous blood transfusion effects of volumes $>760 \mathrm{~mL}$ have been investigated most often. As described by Pandolf et al, ${ }^{20}$ an expected improvement in running performance for $2,4,6,8$, and $10 \mathrm{~km}$ based on these earlier studies was about 7, 15, 30, 45, and 68 seconds, respectively. It is worth mentioning that subjects involved in these investigations were experienced, but not elite-level athletes.

Studies done with elite-level athletes found more moderate improvements in running performance. ${ }^{21-23}$ As was shown with elite-level middle- and long-distance runners, blood boosting could improve performance from $1 \%$ to $4 \%$ depending on the 
(A) $800-m$

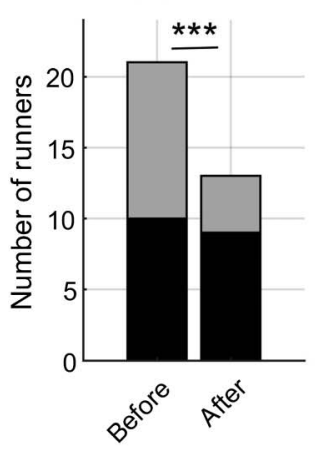

(D) $5,000-m$

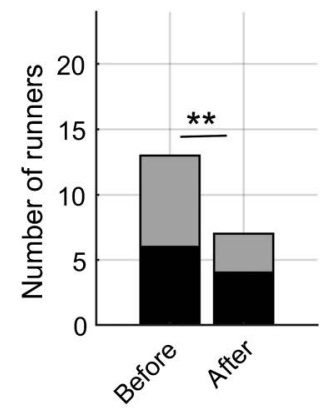

(B) $1500-m$

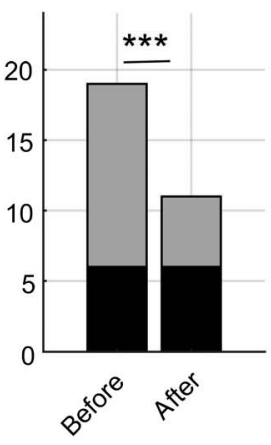

(C) $3000-\mathrm{m} \mathrm{sc}$

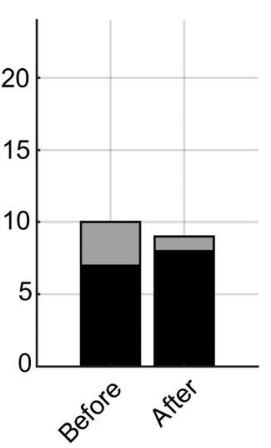

(E) $10,000-m$

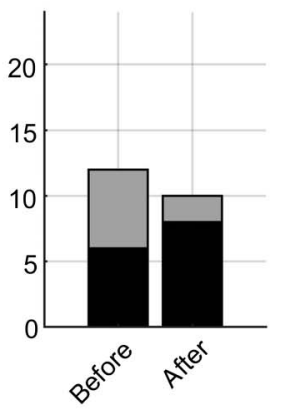

Nonsanctioned runners after the ABP implementation

Sanctioned runners after the ABP implementation

Figure 2 - Number of runners meeting the A-standard criteria in the 2 groups before and after the implementation of the ABP for different events: (A) 800-m, (B) 1500-m, (C) 3000-m sc, (D) 5000-m, and (E) 10,000-m. Events showing statistically significant decrease in the number of A-standard runners after the implementation of the ABP are denoted by asterisks (weighted chi-square statistics, see Supplementary Material [available online]): $* * P<.01 ; * * * P<.001$. Among the A-standard runners, gray and black colors denote the portions of the sanctioned and nonsanctioned runners, respectively. ABP indicates Athlete Biological Passport; sc, steeplechase.

Table 2 Changes in the Number of A-Standard Runners With Implementation of the ABP

\begin{tabular}{|c|c|c|c|c|c|c|c|c|c|c|c|}
\hline \multirow[b]{2}{*}{ Event } & \multirow{2}{*}{$\begin{array}{l}\text { Number of } \\
\text { athletes who } \\
\text { fulfilled A- } \\
\text { standard } \\
\text { qualification in } \\
2008-2012\end{array}$} & \multicolumn{3}{|c|}{$\begin{array}{l}\text { Number of athletes who } \\
\text { competed in 2008-2012 and } \\
\text { were sanctioned with ABP } \\
\text { implementation }\end{array}$} & \multirow{2}{*}{$\begin{array}{l}\text { Number of } \\
\text { athletes who } \\
\text { fulfilled A- } \\
\text { standard } \\
\text { qualification in } \\
2013-2017\end{array}$} & \multicolumn{3}{|c|}{$\begin{array}{l}\text { Number of athletes who } \\
\text { competed in 2013-2017 and } \\
\text { were sanctioned with ABP } \\
\text { implementation }\end{array}$} & \multirow[b]{2}{*}{$\Delta$ qty } & \multirow[b]{2}{*}{$\Delta \%$} & \multirow[b]{2}{*}{$P$} \\
\hline & & ABP & Others & $\begin{array}{c}\text { Proportion } \\
\text { of } \\
\text { sanctioned, } \\
\%\end{array}$ & & ABP & Others & $\begin{array}{c}\text { Proportion } \\
\text { of } \\
\text { sanctioned, } \\
\%\end{array}$ & & & \\
\hline $800 \mathrm{~m}$ & 21 & 9 & 2 & 52 & 13 & 2 & 2 & 31 & 8 & 38.1 & $<.001$ \\
\hline $1500 \mathrm{~m}$ & 19 & 9 & 4 & 68 & 11 & 3 & 2 & 45 & 8 & 42.1 & $<.001$ \\
\hline $3000-\mathrm{m} \mathrm{sc}$ & 10 & 3 & 0 & 30 & 9 & 1 & 0 & 11 & 1 & 10.0 & .346 \\
\hline $5000 \mathrm{~m}$ & 13 & 4 & 3 & 54 & 7 & 1 & 2 & 43 & 6 & 46.2 & .001 \\
\hline $10,000 \mathrm{~m}$ & 12 & 4 & 2 & 50 & 10 & 2 & 0 & 20 & 2 & 16.7 & .050 \\
\hline Total & 75 & 29 & 11 & 53 & 50 & 9 & 6 & 30 & & & \\
\hline
\end{tabular}

Abbreviation: ABP, Athlete Biological Passport; $\Delta$ qty, absolute decrease in the number of A-standard qualification athletes from 2008-2012 to 2013-2017 period; $\Delta \%$, relative decrease in the number of A-standard qualification athletes from 2008-2012 to 2013-2017 period; $P$, Bonferroni-corrected $P$ values for weighted chi-square statistics denoting change in the numbers of A-standard qualification athletes from 2008-2012 to 2013-2017. 
discipline. ${ }^{21}$ By means of autologous blood transfusion, performance increases for the 800 and $1500 \mathrm{~m}$ can reach $3 \%$ to $4 \%$ (2.9 and $4.9 \mathrm{~s}$ ) and $1 \%$ to $2 \%$ for the 5000 and $10,000 \mathrm{~m}$ ( 29 and $50 \mathrm{~s}$ ). The relative increase in performance appears to be higher for shorter distances, likely due to increased oxygen carrying and buffering capacity through the increase of total hemoglobin mass. In the early studies, the autologous blood transfusion was individually adjusted for bodyweight and initial hemoglobin level. The volume of transfusions varied from 750 to $1200 \mathrm{~mL}$ of whole blood. ${ }^{23}$

Less prominent effects of blood transfusion on higher caliber athletes have also been reported by others. ${ }^{24}$ The differences in research protocols and the variety in performance level of subjects involved make the discussion on the effects and volumes of blood transfusion challenging. Also, very few studies have investigated the effects of low-volume blood transfusions on athletic performance, and these results are controversial. ${ }^{24,25}$

The considerable amount of doping cases (Table 2) coinciding with implementation of the ABP provides grounds to speculate that the magnitude of the performance decrease reflects the gains that were available by means of blood doping before. Such performance increases would require transfusion of $>800 \mathrm{~mL}$ of whole blood or the use of erythropoiesis-stimulating substances in significant dosages, both of which are reliably detectable by the ABP nowadays. ${ }^{26,27}$

\section{Changes in the Number of Athletes Able to Qualify for International Competitions}

The number of athletes meeting the highest entry standards for international competitions (European Championship, World Championships, and Olympic Games) also dropped dramatically in most disciplines (Figure 2 and Table 2). There were altogether 75 athletes who fulfilled international qualification standards in 2008-2012, but during 2013-2017, their number decreased to 50 . This decrease happened despite the fact that since 2015, the International Association of Athletic Federations qualification standards were lowered considerably, thus allowing entrance to international competitions for athletes with weaker results. If the performances of the 2013-2017 period had been evaluated by 2008-2012 "A" level standards, it would become apparent that less than 50 athletes had been able to perform at an international level.

The decrease in performance and number of athletes able to qualify for international competition is primarily explained by the considerable number of doping cases (Table 2). Doping cases above were divided into ABP cases and other cases of anti-doping rule violations according to official verdicts. The majority of the doping cases were established by means of the ABP. It is also worth of mentioning that $\mathrm{ABP}$ has been shown to improve the targeting of conventional doping testing and thus also improve testing efficiency. ${ }^{28}$ This effect may not be elucidated by the provided statistics but deserves consideration.

These data are in agreement with previous research that indicated a high prevalence of blood doping in a given subpopulation before implementation of the ABP., ${ }^{4,29}$ However, considering the timing of previous research, these estimates of doping prevalence may not necessarily reflect the current situation.

Changes in performance over given periods could also be affected by a number of additional factors. The lower level of performance during 2013-2017 could be interpreted as a lack of talent in the upcoming generation of athletes. However, it is noteworthy that a portion of athletes banned during 2008-2012 later returned to competition in 2013-2017. Nevertheless, this did not increase the overall level of performance, and none of them were able to reach their previous best performances.

The decrease in performance levels in 2013-2017 could also be interpreted as a deterrent effect of the ABP and effective changes in practices of using illicit drugs and/or means. This notion is supported by external investigations. According to the Independent Commission Report, it was only during spring 2012 when the entourage of athletes involved in doping understood the principles of the ABP and were forced to adjust their behavior. ${ }^{30}$ Thus, awareness of the ABP implementation could indeed be an explanation for changes in practices and the related decrease in performance level.

\section{Conclusion}

Our results are in line with the previous research that showed a significant detrimental effect on performance with the introduction of new anti-doping measures. ${ }^{5-9,13}$ The effects of the ABP on practices of athletes have been described before, ${ }^{11}$ but our study is the first to investigate the relationship of $\mathrm{ABP}$ implementation on athlete performance. We demonstrate that performance results of elite-level female runners of the 800,1500,5000, and 10,000 m decreased significantly with the implementation of the ABP and these changes were $2.33,5.26,31.60$, and 49.83 seconds, respectively. The number of athletes able to qualify for international competition substantially decreased after the implementation of the ABP. Performance profiling can be a potential tool for evaluating anti-doping efficiency. It should be considered to be implemented on a broader scale by anti-doping organizations. ${ }^{12,13}$

\section{Acknowledgments}

Research was funded by the World Anti-Doping Agency (grant number ISF17D04SE) and Urheiluopistosäätiö Foundation.

\section{References}

1. Ljungqvist A. Brief history of anti-doping. In: Rabin O, Pitsiladis Y, eds. Acute Topics in Anti-Doping: Medicine and Sport Science. Basel, Switzerland: Karger; 2017:1-10.

2. Franke WW, Berendonk B. Hormonal doping and androgenization of athletes a secret program of the German Democratic Republic government. Clin Chem. 1997;43(7):1262-1279. PubMed ID: 9216474

3. Kalinski MI. State-sponsored research on creatine supplements and blood doping in elite soviet sport. Persp Biol Med. 2003;46(3): 445-451. doi:10.1353/pbm.2003.0035

4. Sottas P-E, Robinson N, Fischetto G, Dolle G, Alonso JM, Saugy M. Prevalence of blood doping in samples collected from elite track and field athletes. Clin Chem. 2011; 57:762-769. PubMed ID: 21427381 doi:10.1373/clinchem.2010.156067

5. Seiler S, De Koning JJ, Foster C. The fall and rise of the gender difference in elite anaerobic performance 1952-2006. Med Sci Sports Exerc. 2007;39(3):534-540. PubMed ID: 17473780 doi:10.1249/01. mss.0000247005.17342.2b

6. Kruse TN, Carter RE, Rosedahl JK, Joyner MJ. Speed trends in male distance running. PLoS One. 2014;19(9):1-6. 
7. Perneger TV. Speed trends of major cycling races: does slower mean cleaner? Int J Sports Med. 2010;31(4):261-264. PubMed ID: 20148370 doi:10.1055/s-0030-1247593

8. Berthelot G, Tafflet M, Helou NE, et al. Athlete atypicity on the edge of human achievement: performances stagnate after the last peak in 1988. PLoS One. 2010;5(1):e8800. PubMed ID: 20098706 doi:10. 1371/journal.pone.0008800

9. Foster L, Haake S, James DM, Nevill AM. Modelling effects of drug testing procedures on performance trends in the shot put. $J$ Sports Med Doping Stud. 2014;4(5):1-5.

10. Sottas P-E, Robinson N, Rabin O, Saugy M. The athlete biological passport. Clin Chem. 2011;57:969-976. PubMed ID: 21596947 doi:10.1373/clinchem.2011.162271

11. Zorzoli M, Pipe A, Garnier PY, Vouillamoz M, Dvorak J. Practical experiences with the implementation of an athlete's biological profile in athletics, cycling, football and swimming. Br J Sports Med. 2014; 48:862-866. PubMed ID: 24648438 doi:10.1136/bjsports-2014093567

12. Iljukov S, Schumacher YO. Performance profiling-perspectives for anti-doping and beyond. Front Physiol. 2017;8:1102. PubMed ID: 29312004 doi:10.3389/fphys.2017.01102

13. Schumacher YO, Pottgiesser T. Performance profiling: a role for sport science in the fight against doping. Int J Sports Physiol Perform. 2009;4(1):129-133. PubMed ID: 19417234 doi:10.1123/ijspp. 4.1.129

14. Marc A, Sedeaud A, Shipman J, et al. Geographic enrolment of the top 100 in athletics running events from 1996 to 2012. J Sports Med Phys Fitness. 2017;4:418-425.

15. Amro L, Pauly M. Permuting incomplete paired data: a novel exact and asymptotic correct randomization test. J Stat Comput Simul. 2017;87(6):1148-1159. doi:10.1080/00949655.2016.1249871

16. Samawi HM, Vogel R. Tests of homogeneity for partially matchedpairs data. Stat Methodol. 2011;8(3):304-313. doi:10.1016/j.stamet. 2011.01.002

17. Brien A, Simon T. The effects of red blood cell infusion on $10-\mathrm{km}$ race time. JAMA. 1987;257:2761-2765. doi:10.1001/jama.1987. 03390200101022

18. Goforth HW, Campbell NL, Hodgdon JA, Susec AA. Hematologic parameters of trained distance runners following induced erythrocythemia. Med Sci Sports Exerc. 1982;14:174. doi:10.1249/ 00005768-198202000-00346

19. Williams MH, Wesseldine S, Somma T, Schuster R. The effects of induced erythrocythemia upon 5-mile treadmill run time. Med Sci
Sports Exerc. 1981;13(3):169-175. PubMed ID: 7253868 doi:10. 1249/00005768-198103000-00004

20. Pandolf KB, Young AJ, Sawka MN, et al. Does erythrocyte infusion improve two-mile run performance at high altitude? Eur J Appl Physiol Occup Physiol. 1998;79(1):1-6. PubMed ID: 10052653 doi:10.1007/s004210050465

21. Volkov NI. The use of the method of autohemotransfusion aimed at increase of athlete's exercise performance. In Bioenergetics of Sports Activities. Theory and Practice of Physical Culture and Sports. Moscow, Russia; 2010:73-81.

22. Makarova GA. Study of the Influence of Autohemotransfusion on Some Parameters of Functional State in Man [dissertation]. Moscow: Research Center for Blood Transfusion and Hematology; 1975:25.

23. Aulik JV. Autohemotransfusion for Enhancing Work Capacity of Athletes. [dissertation]. Moscow: Research Center for Blood Transfusion and Hematology; 1980:44.

24. Sawka MN, Young AJ, Muza SR, et al. Erythrocyte reinfusion and maximal aerobic power: an examination of modifying factors. JAMA. 1987;257(11):1496-1499. doi:10.1001/jama.1987.03390110072029

25. Bejder J, Breenfeldt Andersen A, et al. Time trial performance is sensitive to low-volume autologous blood transfusion. Med Sci Sports Exerc. 2019;51(4):692-700. PubMed ID: 30407276 doi:10.1249/ MSS.0000000000001837

26. Morkeberg J, Sharpe K, Belhage B, et al. Detecting autologous blood transfusions: a comparison of three passport approaches and four blood markers. Scand J Med Sci Sports. 2011;21(2):235-243. PubMed ID: 19903320 doi:10.1111/j.1600-0838.2009.01033.x

27. Pottgiesser T, Sottas PE, Echteler T, Robinson N, Umhau M, Schumacher YO. Detection of autologous blood doping with adaptively evaluated biomarkers of doping: a longitudinal blinded study. Transfusion. 2011;51(8):1707-1715. PubMed ID: 21382045 doi:10. 1111/j.1537-2995.2011.03076.x

28. Zorzoli M, Rossi F. Case studies on ESA-doping as revealed by the biological passport. Drug Test Anal. 2012;4(11):854-858. PubMed ID: 22514122 doi:10.1002/dta.1340

29. Ulrich $\mathrm{R}$, Pope $\mathrm{Hg}$, Cleret L, et al. Doping in two elite athletics competitions assessed by randomized-response surveys. Sports Med. 2018;48(1):211-219. PubMed ID: 28849386 doi:10.1007/s40279017-0765-4

30. World Anti-Doping Agency. The Independent Commission Report 1. Final Report. November 9, 2015. https://www.wada-ama.org/ en/resources/world-anti-doping-program/independent-commissionreport-1. Accessed July 2019. 